\title{
Films from an Aqueous Suspension of Alkaline Pretreated and Fine Milled Chicken Feathers
}

\author{
Mika Vähä-Nissi*, Panu Lahtinen, Emmi Nuutinen, Timo Kaljunen, Tiina Pöhler \\ VTT Technical Research Centre of Finland Ltd., Espoo, Finland \\ Email: *mika.vaha-nissi@vtt.fi
}

How to cite this paper: Vähä-Nissi, M., Lahtinen, P., Nuutinen, E., Kaljunen, T. and Pöhler, T. (2020) Films from an Aqueous Suspension of Alkaline Pretreated and Fine Milled Chicken Feathers. Materials Sciences and Applications, 11, 27-43.

https://doi.org/10.4236/msa.2020.111003

Received: November 9, 2019

Accepted: December 31, 2019

Published: January 3, 2020

Copyright (c) 2020 by author(s) and Scientific Research Publishing Inc. This work is licensed under the Creative Commons Attribution International License (CC BY 4.0).

http://creativecommons.org/licenses/by/4.0/

\begin{abstract}
The purpose was to test the feasibility of preparing cast films directly from an aqueous suspension of alkaline pretreated and fine milled chicken feathers, and to evaluate the impact of different additives on film formation and the tensile properties of the resulting films. The feather suspension consisted of stiff and sharp-pointed fibers together with more round-shaped fines. Films cast from this suspension were opaque and porous. While films without additives were fragile with drying-induced defects, film formation was improved with additives, especially with ethanolamine and maleic acid at $20 \%$ and $30 \%$ concentrations. A synergistic plasticizing effect was observed with ethanolamine and formamide, and strength of the films was improved with sodium alginate. However, the overall impact of additives on the tensile properties in general and strain at break in specific was limited. This was likely due to the dominating role of the porous film structure and the stiff fibers with a limited reactivity towards the additives.
\end{abstract}

\section{Keywords}

Feather, Films, Mechanical Properties

\section{Introduction}

The target of sustainable economy is to utilize biomass-derived materials for high-volume applications [1]. There is interest, for example, in packaging industry towards more sustainable materials, and biobased plastics and biopolymers have been widely studied. Interesting sources of biomass are by-products from animal sources (legs, heads, bones and feather) currently used for fertilizers, animal feed and pet food.

The global production of broiler meat was estimated to reach 98.4 million tons in 2019 [2]. Feathers constitute up to 10\% out of chicken body weight [3]. 
This equals 23.4 million tons of feather waste annually. Although chicken feathers and keratin, the main component of feathers, have been tested for various applications, there is still a limited use of feathers as a raw material in industrial applications mainly due to the lack of technologies for processing keratin and established routes for utilizing keratin-based products. Most of feather waste is disposed of in landfills, incinerated, or converted into low-value products. Disposal by landfilling or incinerating is, however, becoming increasingly challenging [4]

Chicken feathers vary in form. In general, they are half fibrous material and half central core with a hollow tube structure [5]. Feather components are hydrophobic by nature resulting in poor wettability compared to cotton and wood pulp fibers [6]. Chemically feathers consist of approximately $90 \%$ protein, $8 \%$ water, and $1 \%$ fat [7]. The amino acids are tightly-packed and crosslinked making extraction of keratin challenging [5] [8]. However, keratin can be extracted by chemical and enzymatic means, superheated water, and with ionic liquids [9] [10]. This adds to the complexity of the feather processing.

Processing of keratin into plastic products has been studied extensively [9] [11] [12] [13] [14]. Feathers, on the other hand, have been tested for fabrics, construction materials, composites, and environmental applications [5] [15] [16] [17] [18]. Feathers are not thermoplastic, and chemically modified and hydrolyzed thermoplastic feathers have therefore been prepared and blended with glycerol for making films by compression molding [18] [19] [20] [21]. Chemical modification adds costs and potentially impairs the biodegradability of the feathers [18].

Feather, keratin, and other biopolymer films require additives, such as plasticizers and crosslinking agents, to adjust mechanical properties and moisture stability. Besides glycerol [18] [22] also other plasticizers have been tested for biopolymer films, such as 1,4-butanediol [23], ethanolamine [24] [25] [26], maleic and citric acids [24], sorbitol [27], and urea [26] [28]. Formamide has been used as a softener for paper, gums, and glues, and to prevent cracking in sol-gel coatings [29] [30]. It has also been used as a plasticizer together with urea for thermoplastic biopolymers [31] [32]. Typical crosslinking agents include citric acid [18] [33] and glyoxal [34] [35]. Sodium alginate has been blended with keratin and gelatin, and it crosslinks with different metal ions, especially with calcium [36] [37].

The purpose of this study was to test the feasibility of preparing cast films from an aqueous suspension of alkaline pretreated and milled chicken feathers, and to evaluate the impact of additives on the film formation and the tensile properties of the resulting films.

\section{Materials and Methods}

This study was carried out at VTT between January and August 2019.

\subsection{Materials}

Sanitized chicken feathers were supplied by Grupo Sada (Madrid, Spain). 
Additives tested for the feather suspension included 1,4-butanediol (Sigma-Aldrich), calcium chloride $\left(\mathrm{CaCl}_{2} ;\right.$ Merck), citric acid (Sigma-Aldrich), D sorbitol (Sigma-Aldrich), ethanolamine (Fluka), ferric perchlorate $\left(\mathrm{Fe}\left(\mathrm{ClO}_{4}\right)_{3} \cdot 9 \mathrm{H}_{2} \mathrm{O}\right.$; Fluka), formamide (Sigma-Aldrich), glycerol (Sigma-Aldrich), glyoxal (BASF), magnesium chloride hexahydrate $\left(\mathrm{MgCl}_{2} \cdot 6 \mathrm{H}_{2} \mathrm{O}\right.$; VWR Chemicals), maleic acid (Sigma-Aldrich), sodium alginate (Sigma-Aldrich), sodium hypophosphite monohydrate $\left(\mathrm{NaPO}_{2} \mathrm{H}_{2} \cdot \mathrm{H}_{2} \mathrm{O}\right.$; Alfa Aesar), and urea (Sigma-Aldrich). Additives in solid form were dissolved into water ( $4 \%$ consistency) except sorbitol that was used at $50 \%$ consistency.

\subsection{Methods}

\subsubsection{Preparing Feather Suspension}

Feathers were refined using a combination of mechanical and chemical treatments. Images of original and refined feathers are presented in Figure 1. First, a mild alkali pre-treatment was performed for the feather material. Alkaline treatment was applied with $\mathrm{NaOH}(2 \mathrm{~mol} / \mathrm{kg}$ dry feather $)$ and liquid/feather ratio of 5:1 (W/W) at $50^{\circ} \mathrm{C}$ for $40 \mathrm{~min}$ in order to avoid dissolving. The feather pulp was then washed with deionised water and dried in oven at $105^{\circ} \mathrm{C}$. After the alkaline pre-treatment the feathers were processed using a compactor in which the feathers were pressed through a die using pan grinder rollers and crushed to an approximately $1-3 \mathrm{~cm}$ length to enable better feeding into a grinder.

Pre-treated feathers were soaked in deionised water at $10 \%$ consistency for approximately one hour and dispersed using a ladle. The suspension was then fed into a Masuko Sangyo's Supermasscolloider (Masuko Sangyo Co.) type MKZA10-15J. Three passes were ground with a standard stone type MKE10-46 and three following passes with a modified stone type MKGA10-80. The feather suspension passed six times through the grinder and with increasing operating power from 2.0 to $2.4 \mathrm{~kW}$. The gap width was gradually decreased from $0.3 \mathrm{~mm}$ to $0.2 \mathrm{~mm}$. Operating speed was fixed at $1500 \mathrm{rpm}$. Finally, the ground feather suspension passed four times through the Microfluidizer type M110-EH. The suspension was diluted with deionised water to $6 \%$ consistency before the microfluidization. Two passes were processed through the chambers having diameters of $400 \mu \mathrm{m}$ and $200 \mu \mathrm{m}$ at 1100 bar. Three following passes were processed
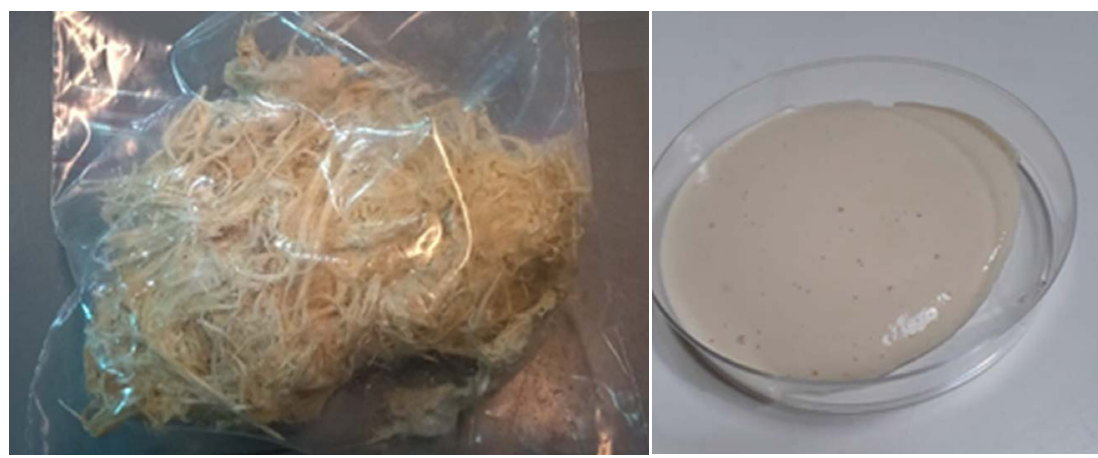

Figure 1. Original feather material (left) and final feather suspension (right). 
through the chambers having diameters of $400 \mu \mathrm{m}$ and $100 \mu \mathrm{m}$ at 1800 bar operating pressure.

The feather suspension was characterized for fiber type and length with an optical microscope (Nikon ECLIPSE Ci) and FiberLab ${ }^{\mathrm{TM}}$ analyzer (Metso Automation), and for consistency, $\mathrm{pH}$ and conductivity.

\subsubsection{Formulations}

The feather suspension was diluted with tap water to $4 \%$ consistency to lower viscosity.

The diluted suspension was mixed carefully for $20 \mathrm{~min}$ at room temperature with a mechanical overhead laboratory stirrer (IKA RW 20 digital). The suspension was placed in a hot water bath at $50^{\circ} \mathrm{C}$ and the plasticizer was added to the suspension. Mixing was continued for at least $10 \mathrm{~min}$ prior adding other possible additives, and the final formulation was mixed for a further $20 \mathrm{~min}$ at $50^{\circ} \mathrm{C}$. Tested formulations are presented in Tables 1-3.

Table 1. Formulations (weight \%) with a single plasticizer.

\begin{tabular}{|c|c|c|c|c|c|c|c|c|c|}
\hline & \multicolumn{9}{|c|}{ Formulation } \\
\hline & 1 & 2 & 3 & 4 & 5 & 6 & 7 & 8 & 9 \\
\hline Feathers & 80 & 80 & 80 & 80 & 80 & 80 & 70 & 70 & 70 \\
\hline \multicolumn{10}{|l|}{ Plasticizers } \\
\hline 1,4-butanediol & 20 & & & & & & 30 & & \\
\hline Ethanolamine & & 20 & & & & & & 30 & \\
\hline Glycerol & & & 20 & & & & & & \\
\hline Maleic acid & & & & 20 & & & & & 30 \\
\hline Sorbitol & & & & & 20 & & & & \\
\hline Urea & & & & & & 20 & & & \\
\hline
\end{tabular}

Table 2. Formulations (weight \%) with ethanolamine and other additives.

\begin{tabular}{|c|c|c|c|c|c|c|c|c|c|}
\hline & \multicolumn{9}{|c|}{ Formulation } \\
\hline & 10 & 11 & 12 & 13 & 14 & 15 & 16 & 17 & 18 \\
\hline Feathers & 75 & 70 & 65 & 60 & 62.5 & 55 & 65 & 64.75 & 65 \\
\hline \multicolumn{10}{|l|}{ Plasticizers } \\
\hline Ethanolamine & 20 & 20 & 30 & 30 & 30 & 30 & 30 & 30 & 30 \\
\hline \multicolumn{10}{|l|}{ Other additives } \\
\hline Citric acid & & & & & 5 & 10 & & & \\
\hline Formamide & 5 & 10 & 5 & 10 & & & & & \\
\hline Sodium alginate & & & & & & & 5 & 5 & \\
\hline Glyoxal & & & & & & & & & 5 \\
\hline $\mathrm{CaCl}_{2}$ & & & & & & & & 0.25 & \\
\hline $\mathrm{NaPO}_{2} \mathrm{H}_{2} \cdot \mathrm{H}_{2} \mathrm{O}$ & & & & & 2.5 & 5 & & & \\
\hline
\end{tabular}


Table 3. Formulations (weight \%) with ethanolamine or maleic acid and other additives.

\begin{tabular}{|c|c|c|c|c|c|c|c|c|c|c|}
\hline & \multicolumn{10}{|c|}{ Formulation } \\
\hline & 19 & 20 & 21 & 22 & 23 & 24 & 25 & 26 & 27 & 28 \\
\hline Feathers & 65 & 60 & 62.5 & 64.9 & 64.75 & 62.5 & 62.5 & 60 & 57.5 & 62.5 \\
\hline \multicolumn{11}{|l|}{ Plasticizers } \\
\hline Ethanolamine & & & & 30 & 30 & 30 & 30 & 30 & 30 & 30 \\
\hline Maleic acid & 30 & 30 & 30 & & & & & & & \\
\hline \multicolumn{11}{|l|}{ Other additives } \\
\hline Citric acid & & & 5 & & & & & & & \\
\hline Formamide & 5 & 10 & & & & & & & & \\
\hline Sodium alginate & & & & 5 & 5 & 5 & 5 & 10 & 10 & 10 \\
\hline $\mathrm{CaCl}_{2}$ & & & & 0.1 & & & & & & \\
\hline $\mathrm{Fe}\left(\mathrm{ClO}_{4}\right)_{3} \cdot 9 \mathrm{H}_{2} \mathrm{O}$ & & & & & & & 2.5 & & & \\
\hline $\mathrm{MgCl}_{2} \cdot 6 \mathrm{H}_{2} \mathrm{O}$ & & & & & 0.25 & 2.5 & & & 2.5 & 5 \\
\hline $\mathrm{NaPO}_{2} \mathrm{H}_{2} \cdot \mathrm{H}_{2} \mathrm{O}$ & & & 2.5 & & & & & & & \\
\hline
\end{tabular}

\subsubsection{Film Casting}

$30-40 \mathrm{ml}$ of each formulation was poured onto three plastic Petri dishes with a diameter of $140 \mathrm{~mm}$ (VWR International). To prevent films from adhering to the Petri dish during drying, a sheet of a one side siliconized $30 \mu \mathrm{m}$ polyester film provided by UPM Raflatac (Tampere, Finland) was first placed at the bottom of the dish. Occasional air bubbles were removed with a single purpose pipette from the suspension. The films were dried in an air circulating oven at $50^{\circ} \mathrm{C}$ at least for overnight. Films from formulations 14 and 15 were also heat treated with an L\&W Rapid Dryer (ABB AB, Lorentzen \& Wettre) at $150^{\circ} \mathrm{C}$ for 5 $\min$.

\subsubsection{Film Characterization}

The films were evaluated visually, and one film of each formulation was photographed.

Cross-sectional surface was prepared from selected films by fracturing a strip of material in liquid nitrogen. The strip was mounted on an aluminum stub with conductive carbon adhesive tape and sputter-coated with approx. $4 \mathrm{~nm}$ of gold-palladium. SEM images (Field Emission Scanning Electron Microscope, Zeiss Merlin) were taken from a tilted $\left(50^{\circ}\right)$ stub to show simultaneously the material surface and the fractured cross-section. The acceleration voltage was 2 $\mathrm{kV}$ and probe current $60 \mathrm{pA}$.

Tensile properties of the films were measured using Lloyd LS5 materials testing machine. Load cell was $100 \mathrm{~N}$, crosshead speed $2 \mathrm{~mm} / \mathrm{min}$, and initial gauge length $20 \mathrm{~mm}$. In total 3 - 4 strips $15 \mathrm{~mm}$ wide of each sample were tested at $23^{\circ} \mathrm{C}$ and $50 \%$ RH. Film thickness was measured twice from each strip tested. Properties of interest were tensile strength (MPa), strain at break (\%), and 
Young's modulus $(\mathrm{MPa})$. Before testing, all specimens were conditioned at $23^{\circ} \mathrm{C}$ and $50 \% \mathrm{RH}$ for several days.

\section{Results}

\subsection{Feather Suspension}

The feather suspension was a viscous fluid with a brownish color. Consistency of the suspension was $5.68 \%, \mathrm{pH} 8.9$, and conductivity $453 \mu \mathrm{S} / \mathrm{cm}$. Based on the microscope images most of the fibrous material was equal or shorter than 100 $\mu \mathrm{m}$, but there were also significantly longer fibers, as presented in Figure 2. The fibers were stiff and sharp-pointed, but there were also round-shaped fines. The FiberLab ${ }^{\mathrm{TM}}$ analyzer detected fibers with length around $100 \mu \mathrm{m}$ (number average $80 \mu \mathrm{m}$ and weight average $110 \mu \mathrm{m}$ ). However, long fibers were excluded from this analysis, although they were obviously present.

\subsection{Film Formation}

Films were prepared successfully from all the formulations, except for formulation 17. Adding $0.25 \%$ calcium chloride to a mixture of feathers, ethanolamine, and sodium alginate had a detrimental impact on colloidal stability, and deposits were formed during mixing. Therefore, this formulation was omitted.

Based on visual evaluation of the films prepared from formulations containing feathers and a single plasticizer (Table 1), ethanolamine and maleic acid produced the most uniform films. Other films had drying-induced patterning, but even these were intact and more uniform than the films prepared without any additives. Figure 3 presents films without additives and films from formulations 1 - 6. The films without additives were fragile and difficult to handle.

Figure 4 shows examples of films from formulations with two or three additives. Formulations with either ethanolamine or maleic acid together with formamide

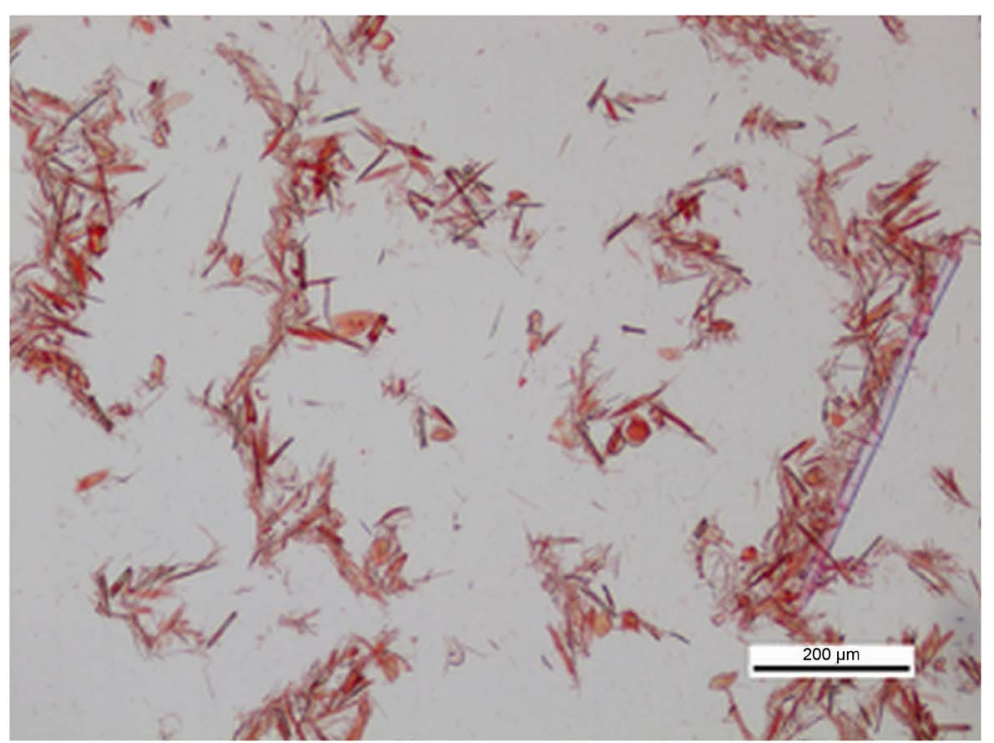

Figure 2. Optical microscope image (magnification 10x) of the feather suspension. 

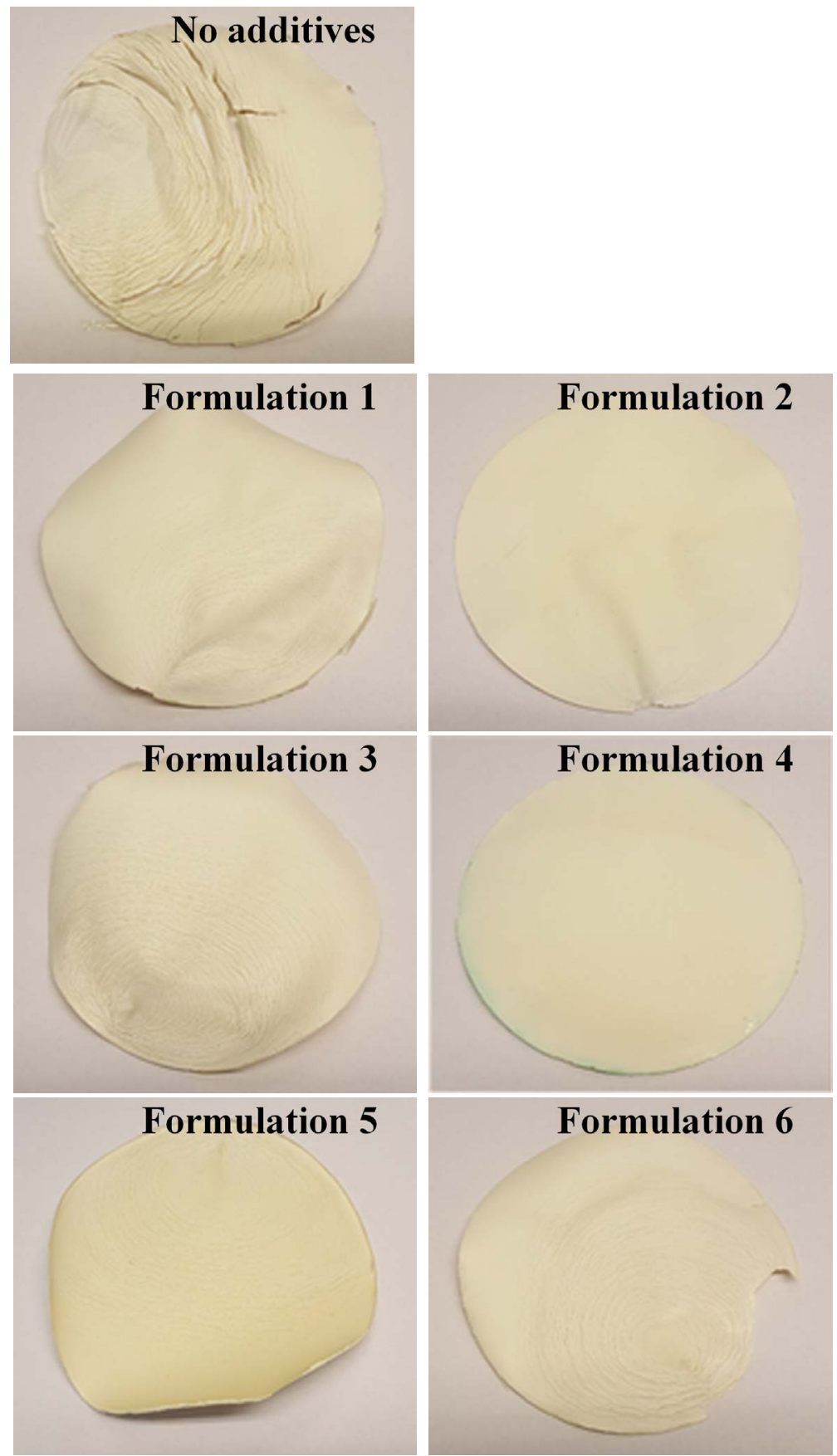

Figure 3. Film without additives and films from formulations 1 - 6 with single plasticizers.

(such as 12 and 19, respectively) resulted in uniform films as did ethanolamine together with sodium alginate (formulation 16) and citric acid, although adding both ethanolamine and formamide resulted in a slight discoloration. Films with both maleic and citric acids with sodium hypophosphite monohydrate (formulation 21) indicated some patterning formed during drying. Most of the films with ethanolamine, sodium alginate, and metal salt (e.g. formulation 23) demonstrated drying-induced shrinkage and slight unevenness. Visually films from 

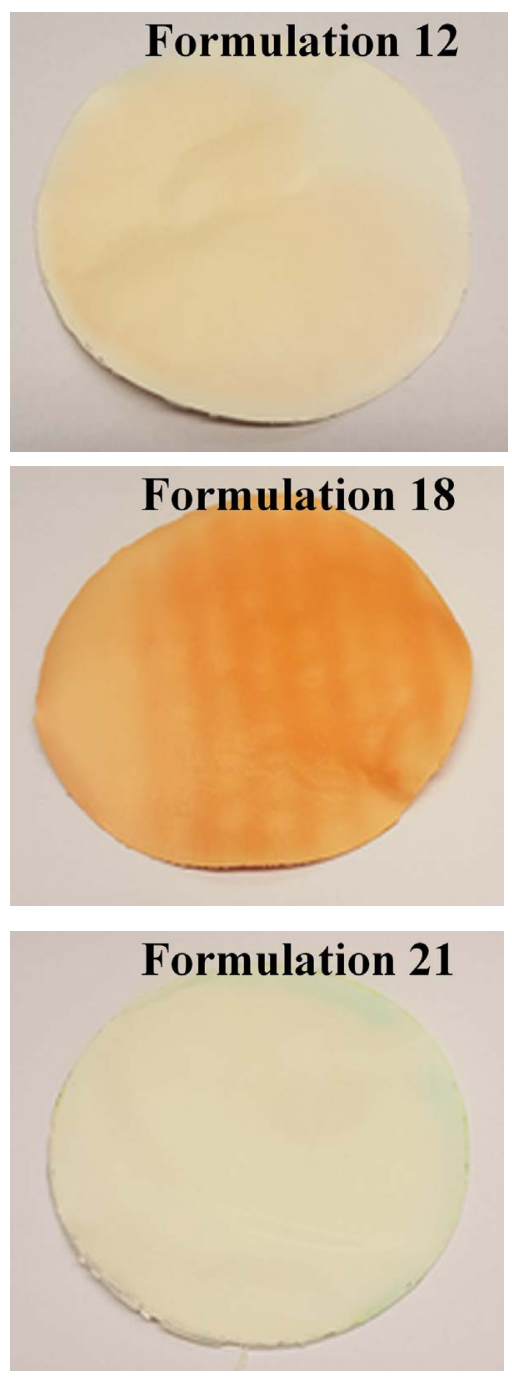

Figure 4. Examples of films from formulations with a plasticizer and other additives.

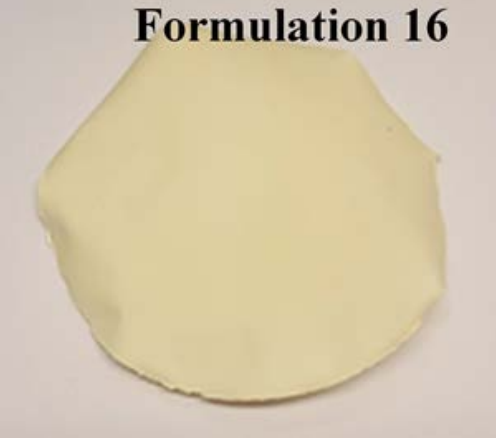

Formulation 19
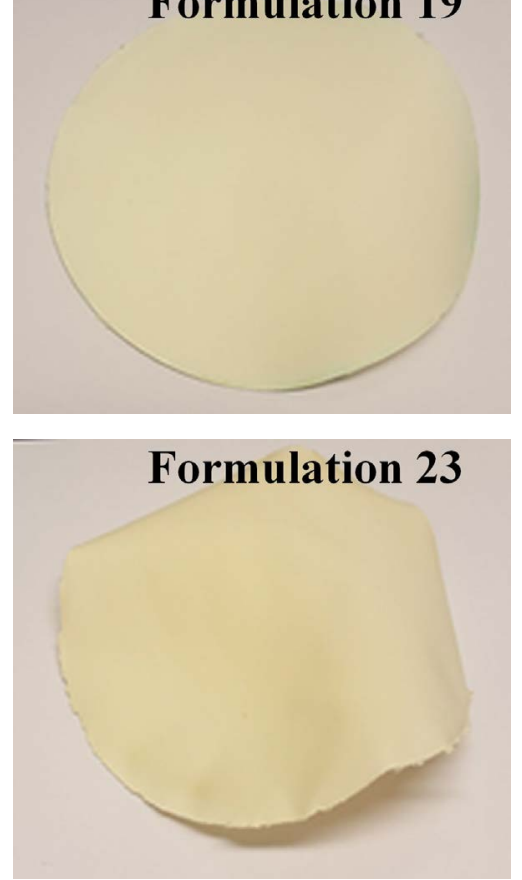

formulation 18 with glyoxal were the most striking with a strong orange color due to an exothermic reaction between ethanolamine and glyoxal.

\subsection{Film Structure}

All the films were opaque caused by the light scattering in a porous film structure. SEM images prepared from films without additives and from formulations 8,12 , and 16 support this (Figure 5). These images show a structure consisting of randomly oriented and relatively stiff and flat fibers covered with a network of fine fibrillated and non-fibrous material on the side in contact with the PET film. No significant differences were observed between the film surfaces or in the crosscuts. Some of the additives must have concentrated within the structure and on the top side of the films.

\subsection{Mechanical Properties}

Films without any additives were too fragile for mechanical testing. This was in 

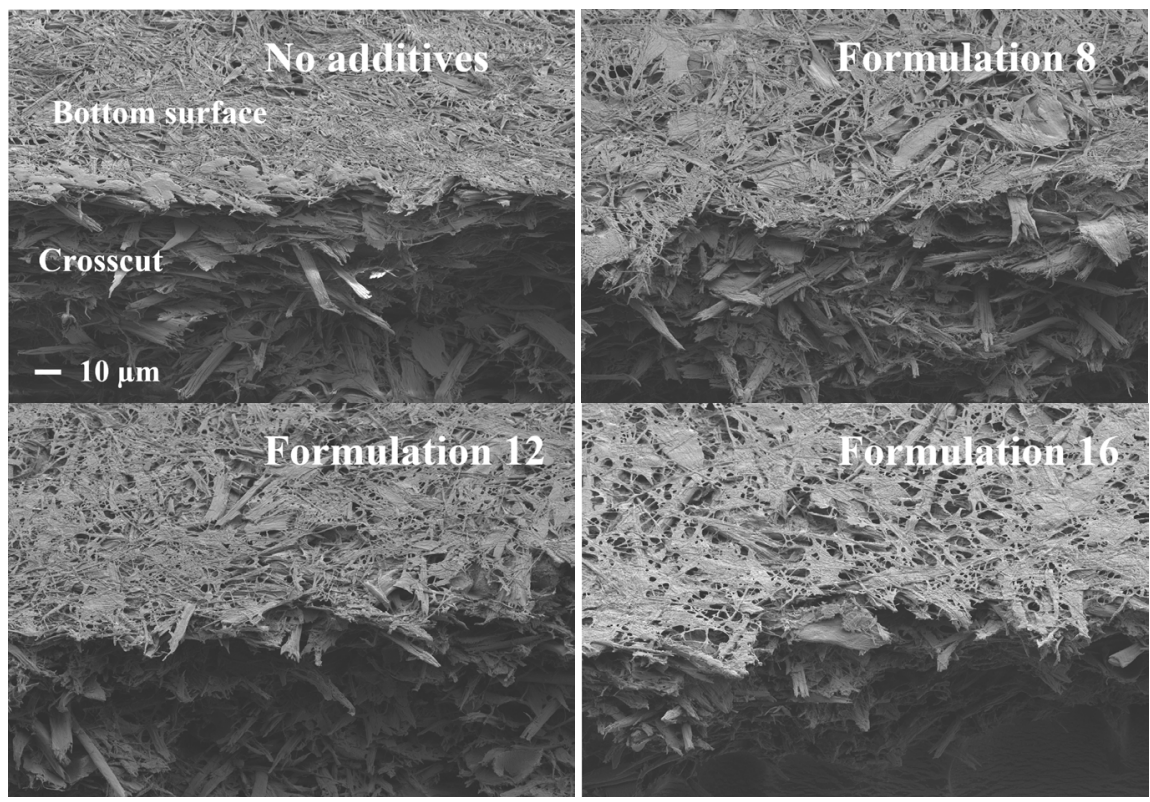

Figure 5. Surface and crosscut SEM images (magnification 500 $\times$ ) of films without additives and films with $30 \%$ ethanolamine (formulation 8 ), 30\% ethanolamine and $5 \%$ formamide (formulation 12), and $30 \%$ ethanolamine and $5 \%$ sodium alginate (formulations 16).

line with previous studies indicating that keratin films even with a small amount of plasticizer ( 0.05 and $0.1 \mathrm{~g}$ of glycerol/g of keratin) were too brittle for testing [38]. In this study, all the films with plasticizers could be measured for the tensile properties. However, bonding between the fibers may dominate the mechanical properties of such porous films.

Figure 6 shows the tensile properties for the films with a single plasticizer. These films were stronger and more brittle than those prepared previously from thermoplastic feathers and keratin (tensile strength 5.2 - 5.9 $\mathrm{MPa}$ [18], and strength 0.3 MPa and Young's modulus $25 \mathrm{MPa}$ [9]). The mechanical properties, except of strain at break, were similar to the carboxymethylated keratin films by Schrooyen et al. [38], but weaker than the grafted feather films without and with $30 \%$ glycerol (206.3 and $55.7 \mathrm{MPa}$, respectively) [19]. With 20\% plasticizer the strongest films were obtained with sorbitol, 1,4-butanediol and ethanolamine, while the films containing maleic acid, urea, and glycerol were among the weakest. Studies with keratin films have shown that increased glycerol concentration decreases the tensile strength and the elastic modulus, while the strain at break increases [9] [38]. Increasing concentration of 1,4-butanediol decreased strength in this study. However, little effect was observed with ethanolamine, and strength increased with an increasing concentration of maleic acid. Maleic acid must have promoted bonding at the fiber-fiber contacts. Maleic acid is known to improve adhesion in polymer-fiber composites [39].

Increasing the amount of maleic acid increased also the strain at break. 1,4-butanediol, glycerol, sorbitol, and urea yielded similar results, while ethanolamine provided slightly lower strain at break, albeit the differences were small. 

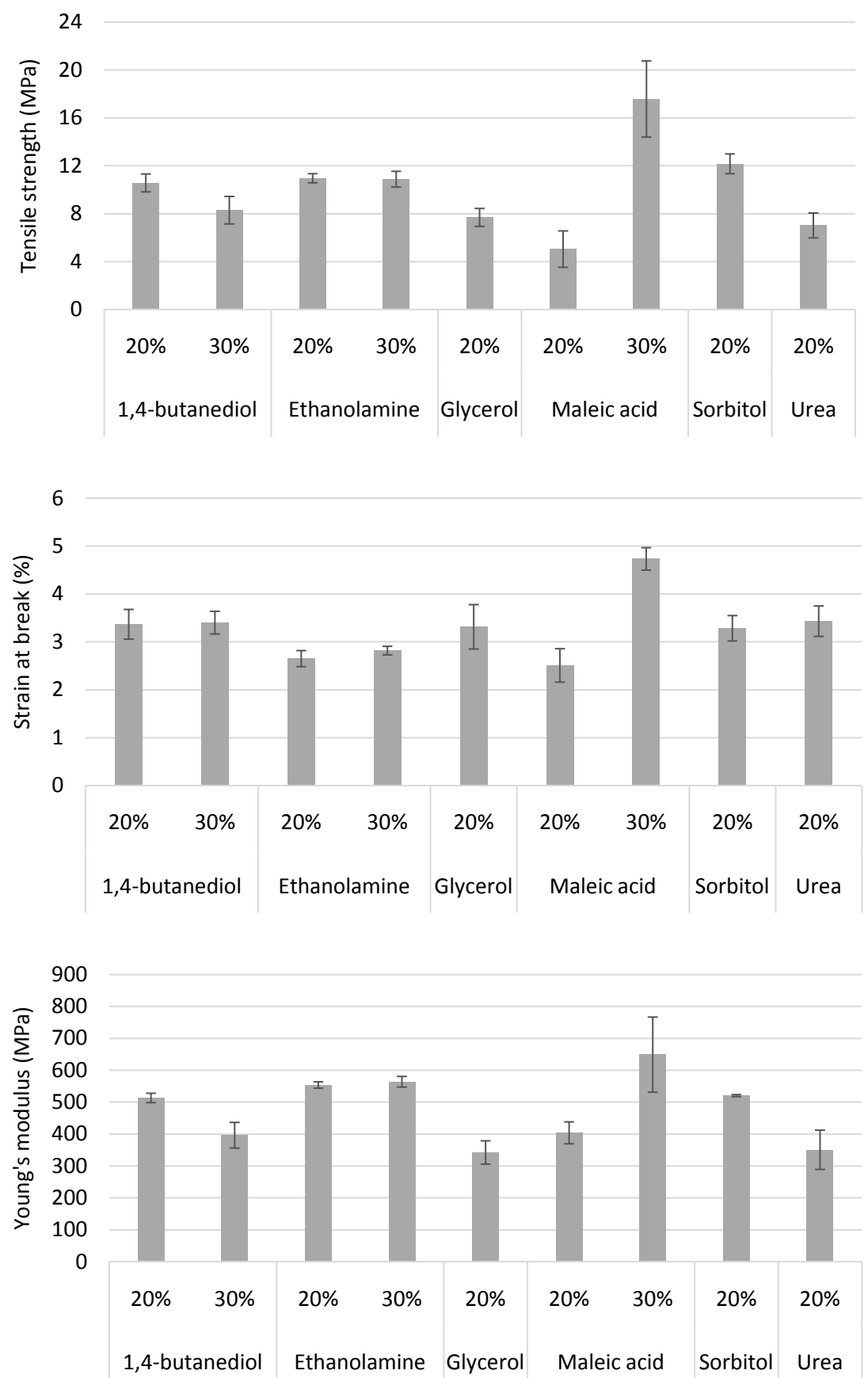

Figure 6. Tensile strength, strain at break, and Young's modulus for films with a single plasticizer.

In general, the level of maximum strain was low. $20 \%$ urea, glycerol and maleic acid, and 30\% 1,4-butanediol resulted in a low elastic modulus. The highest stiffness was obtained with ethanolamine and $30 \%$ maleic acid.

Results from formulations with a blend of ethanolamine and maleic acid together with formamide are presented in Figure 7. At 30\% concentration of ethanolamine and maleic acid the impact of formamide was logical. Tensile strength decreased and strain at break increased. Elastic modulus decreased indicating 

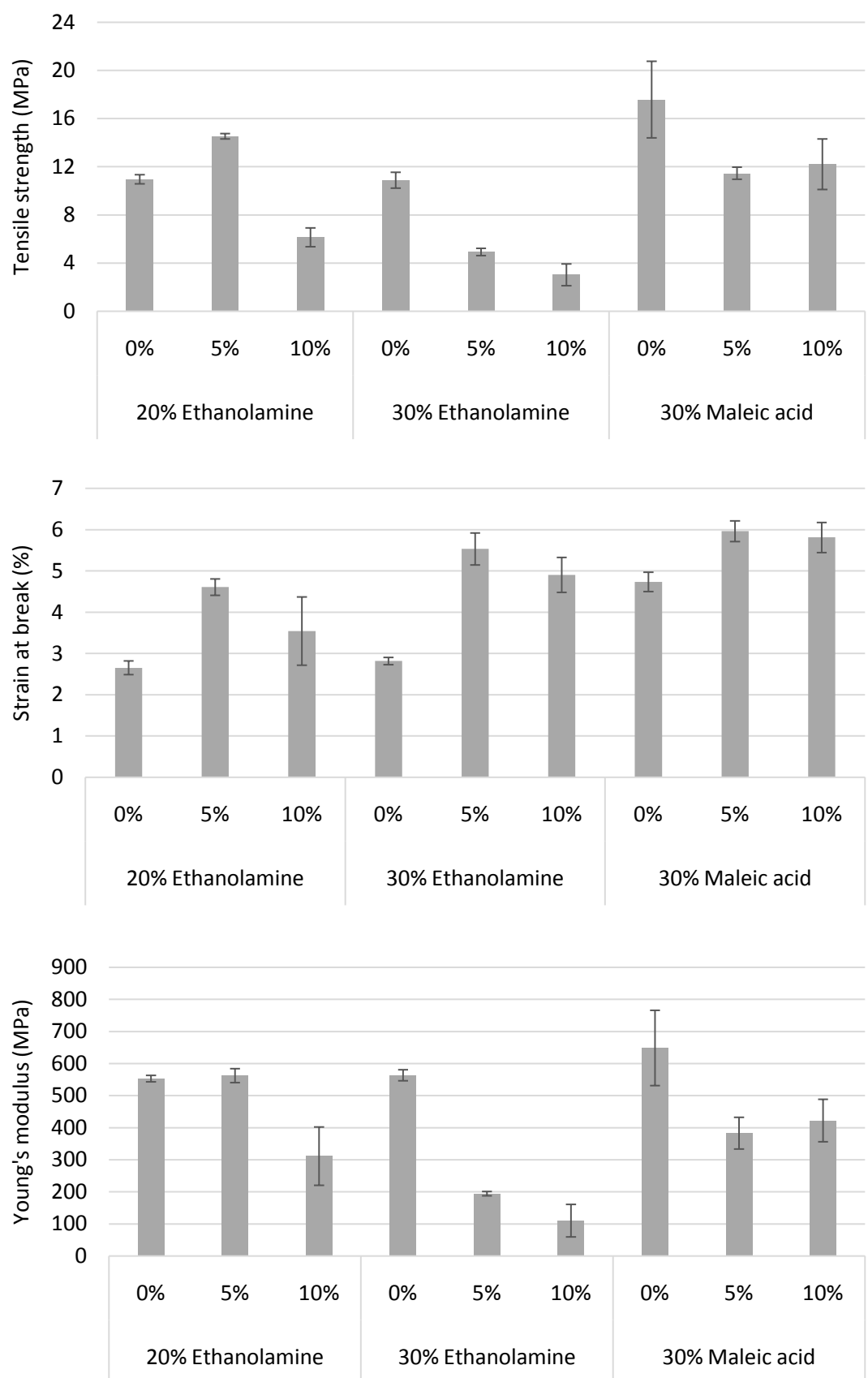

Figure 7. Tensile strength, strain at break, and Young's modulus for films with ethanolamine and maleic acid together with $0 \%, 5 \%$, and $10 \%$ formamide.

increased elasticity at small deformations. At $20 \%$ concentration of ethanolamine more formamide was needed to obtain a plasticizing effect. Formamide together with other plasticizers can provide formulations with good plasticizing effect and improved stability of the plasticizing system. According to Yan et al. formamide can act as a solvent and prevent phase separation [32]. Such a synergistic effect was observed when the properties of films with $20 \%$ ethanolamine and $10 \%$ formamide were compared to those with only $30 \%$ ethanolamine.

Figure 8 shows the impact of other additives on the tensile properties. Together 

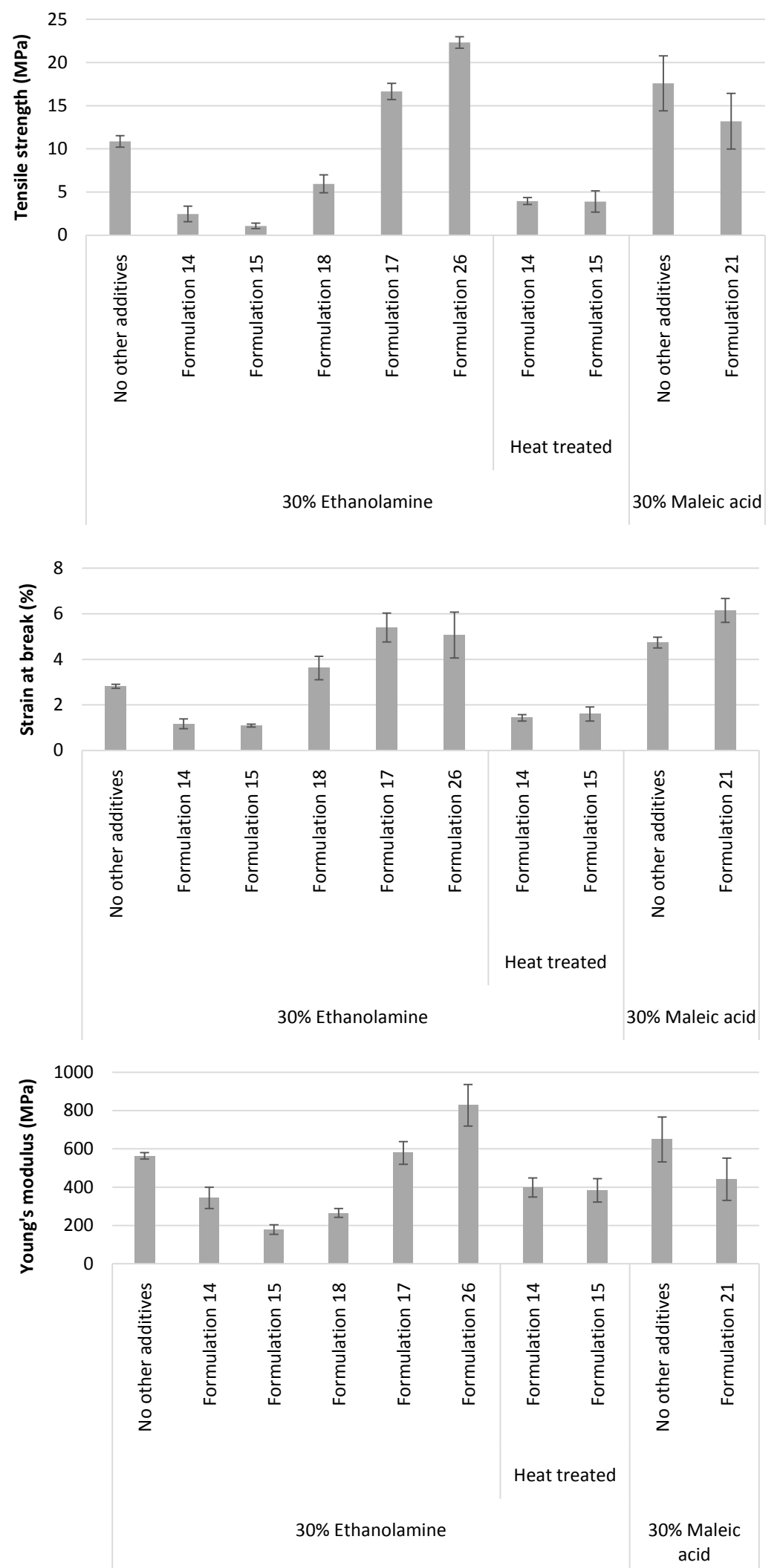

Figure 8. Tensile strength, strain at break, and Young's modulus for films with ethanolamine and maleic acid together with citric acid and $\mathrm{NaPO}_{2} \mathrm{H}_{2} \cdot \mathrm{H}_{2} \mathrm{O}$, glyoxal, and sodium alginate. 
with $30 \%$ concentration of ethanolamine both citric acid and glyoxal decreased all the tensile properties. Additional heat treatment of films with ethanolamine and citric acid had only a minor impact (formulations 14 and 15). According to a previous study with thermoplastic feather films already a $5 \%$ concentration of citric acid can lead to over crosslinking indicated by a decrease in all the three tensile properties [18]. Citric acid together with $30 \%$ maleic acid, on the other hand, increased strain at break, which indicates more of a plasticizing effect (formulation 21). Glyoxal reacted readily with ethanolamine, but this did not increase strength (formulation 18). Using ethanolamine and sodium alginate together (formulations 17 and 26) improved the tensile properties. However, even in this case, the strain at break was less than $6 \%$.

The impact of crosslinking sodium alginate in the formulations with metal ions was tested. Besides a low amount of $\mathrm{CaCl}_{2}$, also other metal cations $\left(\mathrm{Fe}^{3+}\right.$ and $\mathrm{Mg}^{2+}$ ) were tested. As presented in Figure $9, \mathrm{CaCl}_{2}$ increased both tensile strength and elastic modulus. However, strain at break was again less than $6 \%$. A similar impact was reached with a higher concentration of $\mathrm{MgCl}_{2} \cdot 6 \mathrm{H}_{2} \mathrm{O}$ together with $5 \%$ sodium alginate. However, with $10 \%$ sodium alginate doubling the amount of $\mathrm{MgCl}_{2} \cdot 6 \mathrm{H}_{2} \mathrm{O}$ actually decreased tensile strength and elastic modulus, which is likely due to a negative impact of a high addition level of salt on the overall stability of the feather suspension. $\mathrm{CaCl}_{2}$ decreased the strain at break. These results are in-line with the previous results indicating that calcium ions crosslink sodium alginate more efficiently than, for example, magnesium ions [40].

\section{Conclusions}

An aqueous suspension was prepared from chicken feathers using an alkaline pretreatment followed by a three-stage mechanical milling process consisting of crushing, grinding, and microfluidization. The purpose was to avoid costs and complexity related to extraction of keratin or chemical modification of feathers. The resulting suspension consisted of stiff and sharp-pointed fibers together with a smaller number of more round-shaped fines.

Films were cast from the feather suspension. Films without additives were of poor quality and fragile. Film formation was improved with additives, and visually the best films were obtained with $20 \%-30 \%$ of ethanolamine and maleic acid as the single additive or together with formamide, sodium alginate, and citric acid. The films were opaque and porous, which would limit their feasibility for applications where transparency and good barrier properties are essential.

The strongest films were obtained with maleic acid, sorbitol, and ethanolamine as the single additive. Adding formamide together with ethanolamine and maleic acid resulted in a plasticizing effect. Sodium alginate as a secondary additive with ethanolamine had a positive impact on tensile strength with and without cationic metal ions used to crosslink sodium alginate. However, the modest impact of additives on the tensile properties, especially strain at break, can be 

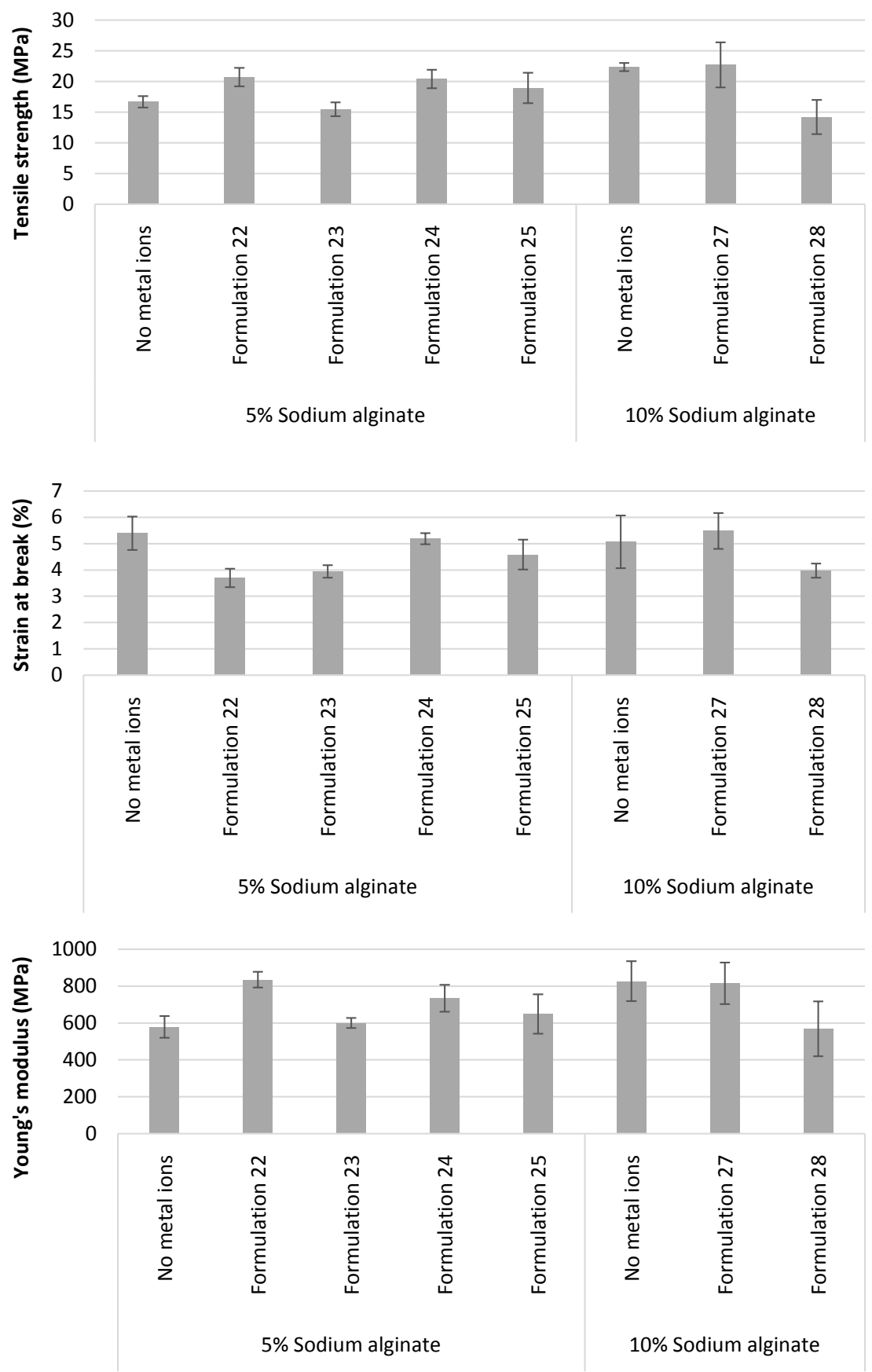

Figure 9. Tensile strength, strain at break, and Young's modulus for films with $30 \%$ ethanolamine, $5 \%$ and $10 \%$ sodium alginate, and different metal cations.

explained by the dominating role of the porous film structure with stiff fibers and low reactivity of the fiber surfaces towards the additives.

\section{Acknowledgements}

This work was supported by KaRMA2020 project. This project has received funding from the European Union's Horizon 2020 Research and Innovation program under Grant Agreement n 723268. 


\section{Conflicts of Interest}

The authors declare no conflicts of interest regarding the publication of this paper.

\section{References}

[1] Johansson, C., Bras, J., Mondragon, I., Nechita, P., Plackett, D., Simon, P., Gregor Svetec, D., Virtanen, S., Giacinti Baschetti, M., Breen, C., Clegg, F. and Aucejo, S. (2012) Renewable Fibers and Bio-Based Materials for Packaging-A Review of Recent Developments. BioResources, 7, 2506-2552. https://doi.org/10.15376/biores.7.2.2506-2552

[2] United States Department of Agriculture (2019) Livestock and Poultry: World Markets and Trade. https://apps.fas.usda.gov/psdonline/circulars/livestock_poultry.pdf

[3] Grazziotin, A., Pimentem, F.A., de Jong, E.V. and Brandelli, A. (2006) Nutritional Improvement of Feather Protein by Treatment with Microbial Keratinase. Animal Feed Science and Technology, 126, 135-144. https://doi.org/10.1016/j.anifeedsci.2005.06.002

[4] Council Directive 1999/31/EC of 26 April 1999 on the Landfill of Waste. https://eur-lex.europa.eu/legal-content/EN/TXT/?uri=CELEX\%3A31999L0031

[5] Salazar, A. and Rios, I. (2009) Sustainable Agriculture: Technology, Planning and Management. Nova Science Publishers, Hauppauge, NY, 353-366.

[6] Tesfaye, T., Sithole, B., Ramjugernath, D. and Chunilall, V. (2017) Valorisation of Chicken Feathers: Characterization of Chemical Properties. Waste Management, 68, 626-635. https://doi.org/10.1016/j.wasman.2017.06.050

[7] Barbut, S. (2015) The Science of Poultry and Meat Processing. Chapter 18, University of Guelph, Ontario.

[8] Poole, A.J., Church, J.S. and Huson, M.G. (2009) Environmentally Sustainable Fibers from Regenerated Protein. Biomacromolecules, 10, 1-8.

https://doi.org/10.1021/bm8010648

[9] Ramakrishnan, N., Sharma, S., Gupta, A. and Alashwal, B.Y. (2018) Keratin Based Bioplastic Film from Chicken Feathers and Its Characterization. International Journal of Biological Macromolecules, 111, 352-358.

https://doi.org/10.1016/j.ijbiomac.2018.01.037

[10] Ji, Y., Chen, J., Lv, J., Li, Z., Xing, L. and Ding, S. (2014) Extraction of Keratin with Ionic Liquids from Poultry Feather. Separation and Purification Technology, 132, 577-583. https://doi.org/10.1016/j.seppur.2014.05.049

[11] Khot, S.N., Lascana, J.J., Can, E., Morye, S.S., Williams, G.I., Palmese, G.R., Kusefoglum, S.H. and Wool, R.P. (2001) Development and Application of Triglycerides-Based Polymers and Composites. Journal of Applied Polymer Science, 82, 703-723. https://doi.org/10.1002/app.1897

[12] Liebner, C.F.E. (2005) Compounding and Molding of Polyethylene Composites Reinforced with Keratin Feather Fiber. Composites Science and Technology, 65, 683-692. https://doi.org/10.1016/j.compscitech.2004.09.030

[13] Wool, R.P. and Sun, X.S. (2005) Bio-Based Polymers and Composites. Elsevier Academic Press, Cambridge, MA, 411. https://doi.org/10.1016/B978-012763952-9/50013-7

[14] Barone, J.R., Schmidt, W.F. and Liebner, C.F.E. (2005) Thermally Processed Keratin 
Films. Journal of Applied Polymer Science, 97, 1644-1651. https://doi.org/10.1002/app.21901

[15] Winandy, J.E., Muehl, J.H., Micales-Glaeser, J.A. and Schmidt, W.F. (2007) Chicken Feather Fiber as Additives in MDF Composites. Journal of Natural Fiber, 4, 35-48. https://doi.org/10.1300/J395v04n01_04

[16] Aluigi, A., Vineis, C., Ceria, A. and Tonin, C. (2008) Composites Biomaterials from Fibre Wastes: Characterization of Wool-Cellulose Acetate Blends. Composites Part $A, 39,126-132$. https://doi.org/10.1016/j.compositesa.2007.08.022

[17] Huda, H. and Yang, Y. (2008) Composites from Ground Chicken Quill and Polypropylene. Composites Science and Technology, 68, 790-798. https://doi.org/10.1016/j.compscitech.2007.08.015

[18] Reddy, N., Chen, L. and Yang, Y. (2013) Biothermoplastics from Hydrolyzed and Citric Acid Crosslinked Chicken Feathers. Materials Science and Engineering C, 33, 1203-1208. https://doi.org/10.1016/j.msec.2012.12.011

[19] Jin, E., Reddy, N., Zhu, Z. and Yang, Y. (2011) Graft Polymerization of Native Chicken Feathers for Thermoplastic Applications. Journal of Agricultural and Food Chemistry, 59, 1729-1738. https://doi.org/10.1021/jf1039519

[20] Hu, C., Reddy, N., Yan, K. and Yang, Y. (2011) Acetylation of Chicken Feathers for Thermoplastic Applications. Journal of Agricultural and Food Chemistry, 59, 10517-10523. https://doi.org/10.1021/jf2023676

[21] Reddy, N., Hu, C., Yan, K. and Yang, Y. (2011) Thermoplastic Films from Cyanoethylated Chicken Feathers. Materials Science and Engineering C, 31, 1706-1728. https://doi.org/10.1016/j.msec.2011.07.022

[22] Martelli, S.M., Moore, G., Paes, S.S., Ganfoldo, C. and Laurindo, J.B. (2006) Influence of Plasticizers on the Water Sorption Isotherms and Water Vapor Permeability of Chicken Feather Keratin Films. LWT-Food Science and Technology, 39, 292-301. https://doi.org/10.1016/j.lwt.2004.12.014

[23] Song, K., Xu, H., Mu, B., Xie, K. and Yang, Y. (2017) Non-Toxic and Clean Crosslinking System for Protein Materials: Effect of Extenders on Crosslinking Performance. Journal of Cleaner Production, 150, 214-223. https://doi.org/10.1016/j.jclepro.2017.03.025

[24] Cao, N., Yang, X. and Fu, Y. (2009) Effects of Various Plasticizers on Mechanical and Water Vapor Barrier Properties of Gelatin Films. Food Hydrocolloids, 23, 729-735. https://doi.org/10.1016/j.foodhyd.2008.07.017

[25] Huang, M., Yu, J. and Ma, X. (2005) Ethanolamine as a Novel Plasticiser for Thermoplastic Starch. Polymer Degradation and Stability, 90, 501-507. https://doi.org/10.1016/j.polymdegradstab.2005.04.005

[26] Ma, X.F., Yu, J.G. and Wan, J.J. (2006) Urea and Ethanolamine as a Mixed Plasticizer for Thermoplastic Starch. Carbohydrate Polymers, 64, 267-273. https://doi.org/10.1016/j.carbpol.2005.11.042

[27] Vieira, M.G.A., da Silva, M.A., dos Santos, L.O. and Beppu, M.M. (2011) Natural-Based Plasticizers and Biopolymer Films: A Review. European Polymer Journal, 47, 254-263. https://doi.org/10.1016/j.eurpolymj.2010.12.011

[28] Wang, J., Cheng, F. and Zhu, P. (2014) Structure and Properties of Urea-Plasticized Starch Films with Different Urea Contents. Carbohydrate Polymers, 101, 1109-1115. https://doi.org/10.1016/j.carbpol.2013.10.050

[29] National Toxicology Program (2008) NTP Technical Report on the Toxicology and Carcinogenesis Studies of Formamide (CAS No. 75-12-7) in F344/N Rats and 
B6C3F1 Mice (Gacave Studies).

https://ntp.niehs.nih.gov/ntp/htdocs/lt_rpts/tr541.pdf

[30] Lenza, R.F.S. and Vasconcelos, W.L. (2001) Preparation of Silica by Sol-Gel Method Using Formamide. Materials Research, 4, 189-194.

https://doi.org/10.1590/S1516-14392001000300008

[31] Ma, X.F., Yu, J.G. and Ma, Y.B. (2005) Urea and Formamide as a Mixed Plasticizer for Thermoplastic Wheat Flour. Carbohydrate Polymers, 60, 111-116. https://doi.org/10.1016/j.carbpol.2004.11.029

[32] Yan, J., Tian, H., Zhang, Y. and Xiang, A. (2015) Effect of Urea and Formamide Plasticizers on Starch/PVA Bioblend Sheets. Journal of Applied Polymer Science, 132, 42311. https://doi.org/10.1002/app.42311

[33] Garavand, F., Rouhi, M., Razavi, S.H., Cacciotti, I. and Mohammadi, R. (2017) Improving the Integrity of Natural Biopolymer Films Used in Food Packaging by Crosslinking Approach: A Review. International Journal of Biological Macromolecules, 104, 687-707. https://doi.org/10.1016/j.ijbiomac.2017.06.093

[34] Galietta, G., Di Gioia, L., Guilbert, S. and Cuq, B. (1998) Mechanical and Thermomechanical Properties of Films Based on Whey Proteins as Affected by Plasticizer and Crosslinking Agents. Journal of Dairy Science, 81, 3123-3130.

https://doi.org/10.3168/jds.S0022-0302(98)75877-1

[35] De Carvalho, R.A. and Grosso, C.R.F. (2004) Characterization of Gelatin Based Films Modified with Transglutaminase, Glyoxal and Formaldehyde. Food Hydrocolloids, 18, 717-726. https://doi.org/10.1016/j.foodhyd.2003.10.005

[36] He, M., Zhang, B., Dou, Y., Yin, G. and Cui, Y. (2016) Blend Modification of Feather Keratin-Based Films Using Sodium Alginate. Journal of Applied Polymer Science, 133, Article ID: 44680. https://doi.org/10.1002/app.44680

[37] Saarai, A., Sedlacek, T., Kasparkova, V., Kitano, T. and Saha, P. (2012) On the Characterization of Sodium Alginate/Gelatine-Based Hydrogels for Wound Dressing. Journal of Applied Polymer Science, 126, E79-E88.

https://doi.org/10.1002/app.36590

[38] Schrooyen, P.M.M., Dijkstra, P.J., Oberthur, R.C., Bantjes, A. and Feijen, J. (2001) Partially Carboxymethylated Feather Keratins. 2. Thermal and Mechancial Properties of Films. Journal of Agricultural and Food Chemistry, 49, 221-230. https://doi.org/10.1021/jf0004154

[39] Rahman, R., Hasan, M., Huque, M. and Islam, N. (2009) Physico-Mechanical Properties of Maleic Acid Post Treated Jute Fiber Reinforced Polypropylene Composites. Journal of Thermoplastic Composite Materials, 22, 365-381. https://doi.org/10.1177/0892705709100664

[40] Topuz, F., Henke, A., Richtering, W. and Groll, J. (2012) Magnesium Ions and Alginate Do Form Hydrogels: A Rheological Study. Soft Matter, 8, 4877-4881. https://doi.org/10.1039/c2sm07465f 